\title{
On the Spatial Diffusion of Knowledge by Universities Located in Small and Medium Sized Towns*
}

\author{
Conceição Rego, António Caleiro
}

Departamento de Economia \& CEFAGE-UE, Universidade de Évora, Évora, Portugal. Email:mcpr@uevora.pt, caleiro@uevora.pt

Received October $1^{\text {st }}, 2009$; revised January $28^{\text {th }}, 2010$; accepted March $29^{\text {th }}, 2010$.

\begin{abstract}
Many studies, provided by diverse authors and institutions, demonstrate that, at a territorial level, development is directly related to the level of education and $R \& D$. Territories with higher development levels are, generally, those that have a higher level of education and $R \& D$. The relationship between the acquisition of knowledge and institutional education is therefore decisive. In this area, the role of universities is fundamental. The retention of university graduates is one of the main ways that the cities and the regions can adopt to retain those endowed with higher propensity to innovation, enterprise spirit and management capacity. Given that higher education institutions, in general, and universities, in particular, are obviously crucial in the process of knowledge increase, it becomes important to analyse how can these institutions act as ways of spatial diffusion of knowledge given that their graduates may migrate to other regions of the country (or for another country). The alleged increased probability of this migration to occur when the university is located in a small or medium sized town makes that analysis also interesting from the viewpoint of the development role that this kind of cities can perform, not only in the adjacent rural areas, but also across all the urban areas of the territory. The focus of our work consists in this analysis, which complements a theoretical approach with an empirical part based upon the results that can be observed for the influence of one university located in a small/medium sized town (the University of Évora) in the spatial diffusion of knowledge through its graduates.
\end{abstract}

Keywords: Human Capital, Small Towns, Spatial Diffusion of Knowledge, Universities

\section{Introduction}

Many studies, provided by diverse authors and institutions, demonstrate that territory development is directly related to the level of education and R \& D characterising those territories. Indeed, territories with higher development levels are, generally, those whose area is characterised by a higher level of education and R \& D. As a consequence, any insufficiency in these territories on those matters constitutes an obstacle to development.

As is well-known education plays an inter-generatio-

\footnotetext{
${ }^{*}$ A previous version of this paper was presented at the conference "Knowledge in Small and Medium Sized Towns: Towns as a Place of Knowledge and Diffusion", which took place at the Universidade do Algarve, Portugal, in December 04-05, 2008. The authors are grateful for the comments obtained there as well as for the subsequent ones. All remaining errors and/or shortcomings are of our own responsibility. This final version is to be related to the research project PTDC/CPEPEC/103727/2008 (Rebuilding the Portuguese higher education system's network: challenges from demographics, economic growth and regional cohesion).
}

nal role. Education is a legacy of one generation to the following one; this being its main social function [1]. It is a medium-term investment, made by the society in general and by households in particular, to the extent that expectations of higher contributions in the future mean forgoing the productive contribution of the young in the present [2]. Parents want their children to receive a highquality education because they understand that in this way they are better preparing them for the labour market.

In the European Union framework, the debate on the role of higher education institutions (henceforth, HEIs) within the knowledge economy is deeply important. The creation of a Europe of knowledge has been defined as main goal for the European Union since the Lisbon Council (March 2000). The Lisboa agenda include many players, in which the universities are certainly to be included. In terms of growth, the knowledge society depends upon the production of new knowledge, its transmission through education and training, and its dissemi- 
nation through information and communication technologies. In this context, universities traditionally play their role in the fields such as those of research and development of their results, due to industrial cooperation and spin-off, education and training, in particular training of researchers, and local and regional development.

As a matter of fact, according to the Communication from European Commission [COM (2003): 58 final] ${ }^{1}$, universities play a key role to the knowledge economy and society. For example, universities employ $34 \%$ of the total number of researchers in Europe and are responsible for $80 \%$ of the fundamental research pursued in Europe. In addition, universities train an increasing number of students with increasingly higher qualifications, which contribute to strengthening the competitiveness of the European economy. Universities also contribute to the objectives of the Lisbon strategy, particularly employment and social cohesion, and to the improvement of the general level of education in Europe: in the total population aged 25-64, the rate of employment of persons holding higher education qualifications stood at $84 \%$ in 2001. On the other hand, the rate of unemployment amongst those which have higher education qualifications remains at 3,9\%, about one third of total of persons with a low qualifications level.

The analysis of local and regional role of HEIs is related to local economic, social and cultural environment. In this sense, HEIs are important instruments of regional development and of strengthening European cohesion. The development of technology centres and science centres, the proliferation of regional cooperation structures between the business sector and the universities, the expansion of university regional development strategies, the regional networking of universities are some dimensions of university activity. In addition, universities can play an important role as a source of expertise and a catalyst for multiple partnerships between economic and social players with multiple networks at the regional and local levels [COM (2003): 58 final].

The contributions of HEIs to regional economies have been made through different ways [3] to identify eight different functions, or outputs, of modern research universities that may potentially lead to economic development impacts:

1) Creation of knowledge;

2) Human-capital creation;

3) Transfer of exiting know-how;

4) Technological innovation;

5) Capital investment;

6) Regional leadership;

7) Knowledge infrastructure production;

8) Influence on regional milieu.

${ }^{1}$ Communication from the Commission, the role of the universities in the Europe knowledge, Commission of the European Communities, Brussels, 05.02.2003.
Obviously, each of the previous outputs may cause a distinct pattern of effects on the regional economy, ranging from the direct and indirect effects of university spending to productivity gains in private enterprises, from the creation of new firms to increases in regional creativity and the capacity to sustain long-term development and growth [3]. According these authors, traditional approaches to assessing the impacts of universities have focused largely on the impacts arising from direct spending and regional investment activities. On the other hand, extensions of these spending-impact studies have branched into considering the effects of human-capital creation and induced regional migration patterns. In this sense, the recent approaches have focused on the basic knowledge creation, knowledge-infra-structure provision, technological innovation, and technology-transfer activities of universities and HEIs, in general [3].

The focus of our work consists in the analysis sketched up, which complements a theoretical approach with an empirical part based upon the results that can be observed for the influence of one university located in a small/ medium town (the University of Évora) in the spatial diffusion of knowledge trough its graduates.

The rest of the paper is structured as follows. From a theoretical point of view, the importance of HEIs in the accumulation and diffusion of human capital through their graduates is analysed in Section 2. From an empirical point of view, it is presented in Section 3 the case of the University of Évora, which is located in small/medium size town, as a source of spatial diffusion of knowledge. Section 4 concludes.

\section{The Importance of Higher Education Institutions in the Accumulation and Diffusion of Knowledge}

The human capital accumulation is a fundamental issue when the goal is to understand the economic and territorial development process. In this sense, the HEIs role is crucial. The HEIs, in general, and universities, in particular, are promotional agents for the development of the regions where they are located, being also sure that some spatial spillover effects are generally observable. Hence, universities are fundamental entities within the development process, capable of generating positive externalities in improving the performance of human capital through the exercise of the functions of education, R \& D and community service.

According to [3], analyses of knowledge production have demonstrated that knowledge, as an output, has qualities that make it unique: knowledge-producing organizations must be considered differently than other large organization with substantial output and employment. External benefits of knowledge production in the form of spatial spillovers lead to increased innovation among other regional firms. In this discussion, the fundamental 
issue is understand how knowledge generated through a university's activities adds value to the local economy, and how relation between universities in their teaching and research activities and other agencies in the local economy contribute to the knowledge creation [4].

Undoubtedly, "Human capital is a fundamental variable in the economic development process: the education of the citizens, more than any material wealth, is the force that mobilizes the cultural spread of a country, gives it influence between nations and attributes to it aptitude to cooperate in the development of a world that is becoming, with each day that passes, closer and more interdependent" [5].

This sentence suggests that we can approach the relations between education and economic development in two ways: firstly, education is responsible for increases in private incomes by enhancing the capacity for obtaining jobs and higher wages; secondly, it generates collective externalities and it stimulates the competitiveness of companies and territories.

Capturing the economic impact of higher education in human capital in a region requires determination of the effect of a specific institution's education on future activity levels as well as the comparison of that effect of what would have occurred had the students been educated elsewhere [6]. According to [6] this type of impacts must include a measure of the discount value of the differences in flows of future economic activity - differences that arise from firms and institutions that are located in the area due to the presence of the university.

The accumulation of capital, physical and human, is a basic condition for sustainable economic growth in the long run, and for the reduction of the divergences of income between countries. Economic success, the first condition for the improvement of the standard of living of the population, translates into the capacity of regions or organizations to mobilize different institutions (companies, organizations, infrastructures of information, systems of incentives, etc.) to support learning. The relation between the acquisition of knowledge and institutional education is decisive. In this area, the HEIs role is fundamental. According to [7], is in the level of education and the employment of graduates in the regional labour market, as well as the level of programmes of professional improvement, that the effects of these institutions will be more significant.

The effect of universities on regional economies can be analysed through the skills base approach. This approach attempts to quantify the impact that HEIs have on the long-run course of a region's economy [8]. The HEIs, through teaching and research, produce skilled workers and increases in technology, both of which can directly increase the wages in the region. Higher wages rates can benefit a region's economy through increased tax revenue, increased consumption and higher rates of saving and investment [8].
The studies in this area were developed, for example, by [9] and [10] as well as by [11] or [12]. According to [8] the research done by [9] and [10] use estimatives of the potential future income stream of graduates who stay to work in the region as the measure of the long-run economic impact of HEIs. Other studies - developed by the Institute for Higher Education Policy, 2005 - in this area looked beyond the immediate effect on wages to consider the less tangible effects that universities have on their communities [8]. In this sense, researchers have established that the graduates are more likely to volunteer in their communities, vote and be aware of political events, require less health care, not smoke, experience lower rates and durations of unemployment, participate in the labour force and not require public assistance at some point in their lives.

[11] developed some research about the several ways in which HEIs can influence the local labour markets. On the one hand, HEIs increase job prospects and the chances of earning higher wages for their graduates; on the other hand, by increasing the average level of knowledge, HEIs can promote an increase in local productivity and in capacity to develop and to implement new technologies, depending on the average level of human capital in the economy. One relevant area in the debate between higher education and labour market gives respect to the kind of skills, i.e., the critical issue in this debate is whether or not the training at first-degree level should be professionalized to impart skills or should provide general education to prepare graduates to respond to their specific circumstances [13].

[4] quoted Felsenstein which identified three tips of 'forward linkage', in the form of changes to the local level of human capital, to the pool of knowledge, and to the attractiveness of the local area to households and firms:

1) Universities raise the level of human capital in their local economy but only to the extent that graduates stay in the local area after completing their studies;

2) Universities add to the knowledge base of the area through a whole series of university-business links, including consultancy and contract research;

3) Universities may also add to the attractiveness of an area through the creation of positive 'quality of life' externalities.

Very close with this proposal, [14] suggests a model to analyse the effect of agglomeration on local university knowledge spillovers, knowledge transfer mechanisms based into three categories:

1) Information transmission via local personal networks of university and industry professionals (local labour market graduates, faculty consulting, university seminars, conferences, student internships, local professional associations, continuing education of employees).

2) Technology transfers through formal business rela- 
tions (university spin-off companies, technology licensing).

3) Spillovers promoted by university physical facilities (libraries, science laboratories, computer facilities) [14].

In this sense, knowledge is an asset in constant formation and accumulation at the university level and can be expected to filter into the local economy in due course, through teaching, consultancy and research; also, a university's international connections can also be important in arresting any inertia that might otherwise contribute to the loss of competitiveness of the local economy [4]. However, it is very likely that geographic proximity may not be a sufficient condition of meaningful university technology transfers [14]. For example, the absence of a 'critical mass' of the enterprises 'side', the lack of producer services, venture capital and entrepreneurial culture may explain the dissonance in local spillover effect, i.e., HEIs and local companies and other institutions should have the same 'language' and understand their complementarities in order to promote the rising of territorial knowledge effects.

One of the fundamental factors in the economic success of a region is the extent it can attract or retain graduates, in that these citizens generally become more productive. A great part of the economic effect of the HEIs depends in the decisions of its graduates not to migrate [12]. It must be admitted that higher education increases the probability of migration, in so far as graduates are better equipped to compete in the national and international labour markets and thus leave the region where they have studied. Migration decisions are based on job chances: if a given region does not have a tradition of growth of jobs in specific sectors, but has graduates in these areas, then these will be potential emigrants. At the same time, the increase in the knowledge of the HEI cannot influence the development of economies if there is a lack of adequate and available jobs for graduates.

So, the retention of graduates is one of the main means that the cities and the regions can adopt to hold in to those endowed with sensitivity to innovation, enterprise spirit and management capacity. Retention rates show, however, a relationship of many factors: the capacity of the HEIs to offer studies and training that take into account the needs of the local and regional economy; stability, diversity and importance of the economic regional base, the context of the national or regional economy, the origin of the students, the type of educational establishment and the economic and social context of the students.

Given that HEIs, in general, and universities, in particular, are obviously in the process of knowledge increase, it becomes important to analyse how can these institutions act as means of spatial diffusion of knowl-

\footnotetext{
${ }^{2}$ From a different, but complementary, perspective, [16] analyse the importance of science in the diffusion of knowledge. See also [17], who consider the case of India when analysing the diffusion of knowledge through migration of scientific labour.
}

edge given that they graduates may migrate for other regions of the country (or for another country). The alleged increased probability of this migration to occur when the university is located in a small or medium sized town makes that analysis also interesting from the viewpoint of the development role that this kind of towns can perform, not only in the adjacent rural areas, but also across all the urban areas of the territory.

\section{The Case of the University of Évora}

The University of Évora is located in a small/medium size town, i.e. in Évora, which has a population of about 55000 inhabitants. Évora is the main urban agglomeration of the 'Alentejo Central' (NUT III) as well as of the province of Alentejo, which is the least densely populated region of Portugal and one of the poorest in the European Union. The evidently distinct behaviour of Évora, in economic and demographic terms, from the rest of the Alentejo (Central) is due to some factors, in which the importance of the University of Évora can undoubtedly be included.

Being the main institution of higher education and of research and development ( $R$ \& D) located in the Alentejo, the University of Évora has increased responsibilities in the areas of higher learning, research and community service. With reference to education and research, the areas prioritised for development are Natural Sciences, Social and Human Sciences, Economics and Management as well as Agrarian and Veterinarians Sciences.

In the area of the activities of community service, the University of Évora offers services at the level of training and consultancy, or by promoting the insertion of graduates in the regional labour market. It also participates in many regional entities, at the level of the respective administrations, seeks regional partners for the institution through participation in activities of education or research, and maintains a special relationship with the schools involved in other levels of education. The accomplishment or promotion of cultural and similar activities has been one of the most systematic ways used for involving the city.

As a matter of fact, after the re-establishment of the University in 1979, the presence of this HEI has contributed decisively to the modification of the dynamic of the city through the increasingly significant presence of students, many of them coming from regions other than the Alentejo (see [15]). Particularly in the 1980s and 1990s the University of Evora has contributed to fulfil the needs of the job market in Évora and throughout all the Alentejo through its graduates. This migration of human capital, therefore of knowledge, towards Évora (and Alentejo) can therefore be viewed as complementary to the economic-base relevance of the University of Évora (see [12] for an argument of how the skill-base approach, which is considered here, does not disregard the traditional economic-base approach, but, indeed, adds to it). ${ }^{2}$ 
Having said that, it is our point that the diffusion of knowledge that is due to the University of Évora can be proxified by a positive proportion of the number of graduates that enter the job market in which they exert a profession requiring the knowledge and competencies earned at the University. In doing so we distinguish four territories of diffusion: Évora, (rest of) Alentejo Central, (rest of) Alentejo and the (rest of) Portugal.

In accordance to our main goal, it is illuminating to present a figure showing those four territories of diffusion, not only in terms of their location in the country but also in terms of their areas, as both aspects are clearly important in the understanding of the real importance of the spatial process of diffusion of knowledge by the graduates of the University of Évora. Figure 1 thus shows all Portugal, the NUT III Alentejo Central (in red), the location of the UE, and the location of the Alentejo (which is composed by the Alentejo Central and the 4 NUTs III (out of the 5) surrounding the Alentejo Central with largest areas.

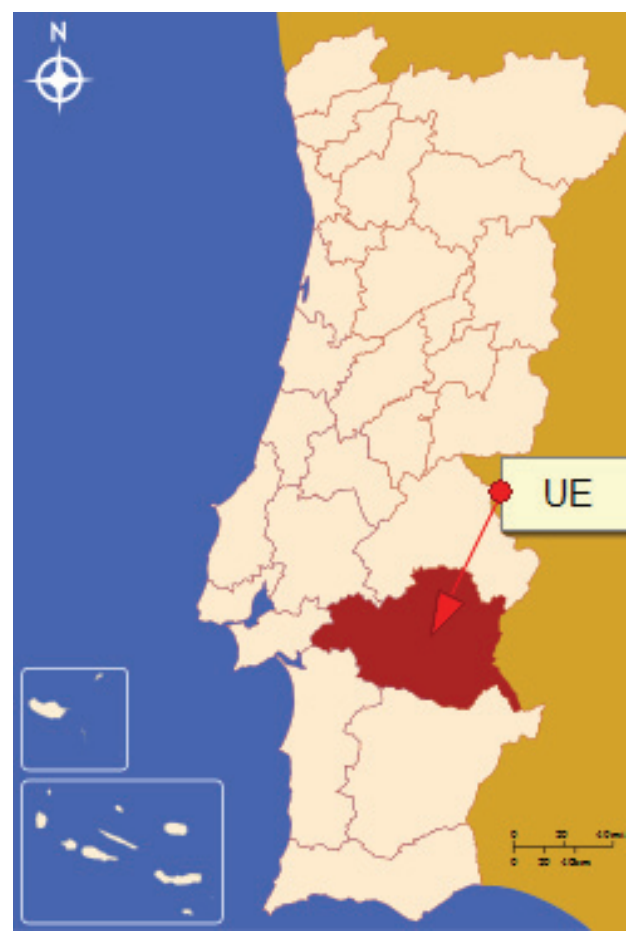

Figure 1. The four territories of diffusion

\footnotetext{
${ }^{3}[19]$ also use a Markov chain approach in order to analyse the role of knowledge in the sequential processes of negotiation.

${ }^{4}$ As the values in the transition matrix are obtained dividing each of values in Table 1 by the sum of each row, each row in Table 1 adds to one.

${ }^{5}$ This stationary distribution corresponds to the percentages that in the long-run, each of the (four territories in the case) would benefit from the spatial diffusion of knowledge. As such those values can be seen as the steady-state solution of the dynamic process, which is supposed to be ruled by the transition matrix.
}

As pointed out by some authors, one fruitful source of knowledge diffusion is the mobility in the job market (see [18]). In order to consider this issue, we take the results of a recent enquire to the graduates of the University of Évora as representative. In what concerns the job market, the responses to the question: "Where did you get your first job" vs. "Where are you working nowadays?" can be consulted in Table 1.

From Table 1 it can easily be inferred the importance of Évora as an attraction pole, despite being also evident that many graduates do indeed take their knowledge with them to other parts of the country.

As some authors recognise, the diffusion of knowledge can be measured by the analysis of the migration between jobs, which, being a dynamic process, can be analysed from a Markov chain point of view. ${ }^{3}$ Following this approach, the transition matrix corresponding to the data is given in Table 2 . $^{4}$

Under the usual hypothesis, the stationary distribution of the dynamic process is given by \{Évora $=15 \%$; Alentejo Central $=5 \%$; Alentejo $=13 \%$; Portugal $=67 \%\}^{5}$ Plainly, these figures have to be made proportional to the area of the four territories of diffusion, in order to accurately point out the importance of the diffusion of knowledge due to the University of Évora via its graduates. The values obtained after dividing those values by the areas (measured in $\mathrm{Km}^{2}$ ) of their corresponding territories are represented in Figure 2, this being constructed in order to include the territory with less area in the one with the area immediately above, i.e. obviously, Évora in the Alentejo Central, the Alentejo Central in the Alentejo and the Alentejo in Portugal.

Being understood as a rainbow (cold/hot) plot, Figure 2 clearly point out the importance of the diffusion of knowledge particularly in Évora and in the rest of Portugal, that can be associated to the graduates of the University of Évora, being also observable that the (rest of the) Alentejo is the territory where that importance is less evident.

Table 1. The dynamics between jobs

\begin{tabular}{|c|c|c|c|c|c|}
\hline & \multicolumn{4}{|c|}{ Current job } \\
\hline & & Évora & Alentejo Central & Alentejo & Portugal \\
\hline \multirow{4}{*}{$\frac{7 ᄁ}{\bar{n}}$} & Évora & 201 & 12 & 23 & 66 \\
\hline & Alentejo Central & 21 & 74 & 16 & 30 \\
\hline & Alentejo & 14 & 11 & 169 & 53 \\
\hline & Portugal & 33 & 12 & 22 & 581 \\
\hline
\end{tabular}

Table 2. The transition matrix

\begin{tabular}{|ll|cccc|}
\hline & & \multicolumn{4}{c|}{ Current job } \\
\cline { 3 - 6 } & & Évora & Alentejo Central & Alentejo & Portugal \\
\cline { 3 - 6 } & Évora & 0,666 & 0,040 & 0,076 & 0,219 \\
$\overline{\bar{y}}$ & Alentejo Central & 0,149 & 0,525 & 0,113 & 0,213 \\
$\frac{\overrightarrow{0}}{\circ}$ & Alentejo & 0,057 & 0,045 & 0,684 & 0,215 \\
& Portugal & 0,051 & 0,019 & 0,034 & 0,897 \\
\hline
\end{tabular}




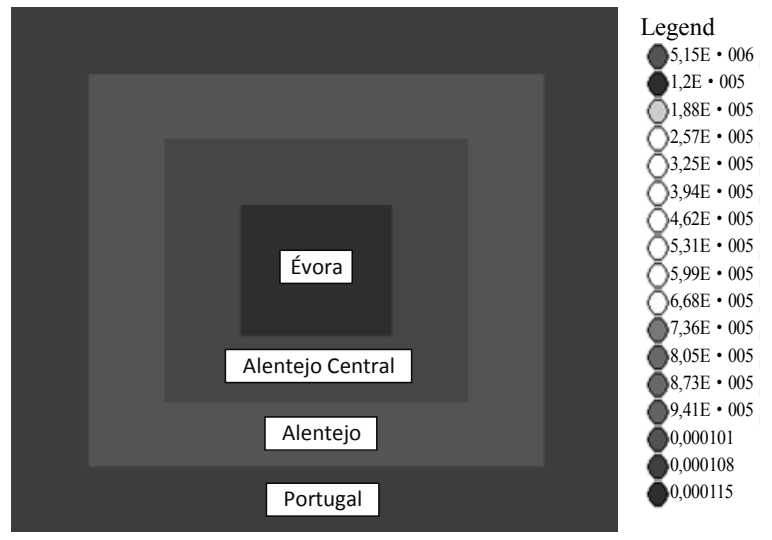

Figure 2. The spatial diffusion of knowledge by the University of Évora

\section{Conclusions}

The HEIs can contribute to improving and to consolidating the regional knowledge capacity, through mechanisms in the area of education and research. The coherence of regional knowledge creation and diffusion system will become more robust through a rigorous selection of courses and curricula adapted to regional technological needs, and by supporting the development of a culture using local techniques (accumulation of codified knowledge), i.e., more adapted to the local and regional labour market characteristics. From this point of view, the dynamics of local enterprises are crucial, particularly through the employment promotion and retaining the graduates.

Also, the processes of creation, acquisition, adaptation and diffusion of new knowledge developed in the universities, can consolidate the relationship capacity of the region where they are inserted, developing projects that involve the sharing of co-operation between companies. This can contribute to diminishing the distance between science, technology and the society, between pure and applied research and between the discovery of new technologies and the development of products and viable processes of production (facilitating the accumulation of tacit knowledge).

In empirical terms, the main conclusion is the University of Évora is an important sources of knowledge diffusion in terms of the small/medium sized town where it is located (i.e. Évora), despite not being ignorable the importance in terms of the rest of the country. From this point of view, the importance of the University of Évora, in terms of spatial diffusion of knowledge, is to be added to the economic impact of this university as measured in $[20]{ }^{6}$ As a matter of fact, when adding up also the diffusion of knowledge that is certainly due to the scientific activity of the academic staff of the University of Évora,

${ }^{6}$ See also [21] and [22]. the importance of this HEI is obviously closer to its real figure.

As directions for further research we would like to study an issue that despite being apparently/intuitively important could not be studied due to lack of information in the enquiry (which may require the application of another enquiry). As a matter of fact, in order to better understand the regional effects of the University of Évora, it seems crucial to know if graduates, during their study period, had some contact with enterprises operating in the region of Évora and/or in the region of actual residence, thus favouring the admission of students to business jobs after their graduation degrees.

\section{REFERENCES}

[1] D. Thomas, "Education and the Role of the University in Economically Developing Regions," Higher Education Policy, Vol. 8, No. 2, 1995, pp. 51-62.

[2] R. Lopes, "Competitividade, Inovação e Territórios," Celta Editora, Lisbon, 2001.

[3] J. Drucker and H. Godstein, "Assessing the Regional Economic Development Impacts of Universities: A Review of Current Approaches," International Regional Science Review, Vol. 30, No. 1, January 2007, pp. 20-46.

[4] H. Battu, J. Finch and D. Newlands, "Integrating Knowledge Effects into University Impact Studies: A Case Study of Aberdeen University," Report Prepared for the Principal for Aberdeen University, Department of Economics, University of Aberdeen, 1998.

[5] V. Crespo, "Uma Universidade para os anos 2000, o Ensino Superior numa Perspective de futuro," Editorial Inquérito, Lisbon, 1993.

[6] M. Blackwell, S. Cobb and D. Weinberg, "The Economic Impact of Educational Institutions: Issues and Methodology," Economic Development Quarterly, Vol. 16, No. 1, 2002, pp. 88-95.

[7] J. Goddard, "Contribuition au Développement National et Regional," UNESCO, Conférence Mondiale sur l'enseignement Supérieur, Paris, 1998.

[8] M. P. Nagowsky, "Assessing the Economic Impact of Higher Education Institutions in New England," Memorandum, New England Public Policy Center, Federal Reserve Bank of Boston, Boston, 2006. http:// www.bos.frb. org/economic/neppc

[9] B. Bluestone, "UMASS Boston: An Economic Impact Analysis," John W. McCormack Institute of Public Affairs, The University of Massachusetts, Boston, 1993.

[10] M. C. Berger and D. A. Black, "The Long Run Economic Impact of Kentucky Public Institutions of Higher Education," University of Kentucky Center for Business and Economic Research, Lexington, 1993.

[11] P. Beeson, and E. Montgomery, "The Effects of Colleges and Universities on Local Labor Markets," Review of Economics and Statistics, Vol. 75, No. 4, 1993, pp. 753761. 
[12] R. H. Brown and M. T. Heaney, "A Note on Measuring the Economic Impact of Institutions of Higher Education," Research in Higher Education, Vol. 38, No. 2, 1997, pp. 229-240.

[13] M. K. Mayanja, "A Comparative Study of Makerere University Graduates of the Faculties of Arts and Sciences," AAU Research Paper Series, Study Program on Higher Education Management in Africa, 2001. http://www.aau. org/studyprogram/pdfiles/mayanja3.pdf

[14] A. Varga, "Local Academic Knowledge Spillovers and the Concentration of Economic Activity," Conference Paper 493, $38^{\text {th }}$ Congress of the European Regional Science Association, Vienna, 1998. http://www.ersa.org/ersaconfs/ersa98/papers/493.pdf

[15] A. Rego and A. Caleiro, "Universities and Economically Depressed Regions: How 'Attractive' is the University of Évora?" Conference Paper 23, European Regional Science Association, 2004. http://www.ersa.org/ersaconfs/ ersa04/PDF/23.pdf

[16] O. Sorenson and L. Fleming, "Science and the Diffusion of Knowledge," Research Policy, Vol. 33, No. 10, 2004, pp. 1615-1634.

[17] A. Kale, D. Wield and J. Chataway, "Diffusion of Knowledge through Migration of Scientific Labour in India," Paper Given at the SPRU 40th Anniversary Conference, The Future of Science, Technology and Innovation Policy, mimeo, 2006.

[18] A. M. Franco and D. Filson, "Spin-Outs: Knowledge Diffusion through Employee Mobility," RAND Journal of Economics, Vol. 37, No. 4, 2006, pp. 841-860.

[19] L. R. Weingart, M. J. Prietula, E. B. Hyder and C. R. Genovese, "Knowledge and the Sequential Processes of Negotiation: A Markov Chain Analysis of Response-inKind," Journal of Experimental Social Psychology, Vol. 35, No. 4, 1999, pp. 366-393.

[20] C. Rego, "Impactes da Universidade de Évora: Estudo de Alguns efeitos no Território Envolvente," Tese de Doutoramento, Universidade de Évora, 2003.

[21] A. Caleiro and C. Rego, "Os Efeitos Económicos das Universidades nas Regiões: Porque se deve Usar a Análise Input-Output na sua Medição?” Paper Given at the XI Congresso da Associação Portuguesa para o Desenvol-vimento Regional, Universidade do Algarve, Faro, September 16-18, 2005.

[22] A. Rego, "Universities in Peripherals Countries: Researching 'in the Regions' or 'for the Regions'? - Some Evidence Based on the University of Évora Experience," Paper Presented at the UNESCO Forum for Higher Education, Research and Knowledge: "Universities as Centres of Research and Knowledge Creation: An Endangered Species? UNESCO, December 2006. 